\title{
Relationships between FSH and ovarian follicular waves during the last six months of pregnancy in cattle
}

\author{
O. J. Ginther ${ }^{1}$, K. Kot ${ }^{1}$, L. J. Kulick ${ }^{1}$, S. Martin ${ }^{2}$ and M. C. Wiltbank ${ }^{3}$ \\ ${ }^{1}$ Department of Animal Health and Biomedical Sciences, ${ }^{2}$ Department of Statistics and ${ }^{3}$ Department of \\ Dairy Science, University of Wisconsin-Madison, Madison, Wisconsin 53706, USA
}

\begin{abstract}
Follicles were monitored daily by ultrasound and blood samples for FSH assay were collected daily from eight heifers from day 90 of pregnancy to the emergence of the first postpartum follicular wave. Follicles $\geq 6 \mathrm{~mm}$ in diameter emerged in groups or waves in each heifer $(P<0.005)$. Follicular waves developed rhythmically throughout pregnancy, except that follicles $\geq 6 \mathrm{~mm}$ were not detected during the last $21.6 \pm 2.4$ (mean \pm SEM) days of pregnancy. The characteristics of the first follicular wave after day 90 were similar to previous reports for days 10-100. However, between months 4 (days 90-119) and 5, there was a decrease $(P<0.05)$ in monthly means for maximum diameter $(\mathrm{mm})$ of largest (11.1 \pm 0.5 versus $9.5 \pm 0.5$ ) and second largest $(8.0 \pm 0.3$ versus $6.9 \pm 0.2)$ follicles, duration of the interwave interval ( $8.1 \pm 0.4$ versus $6.6 \pm 0.3$ days), and number of follicles per wave (3.7 \pm 0.4 versus $2.5 \pm 0.4$ ). Averaged over all follicular waves during months $4-9$, the concentrations of FSH normalized to the emergence of a follicular wave increased $(P<0.05)$ over the 3 days before emergence, reached peak values on the day of emergence of the future dominant follicle at $4 \mathrm{~mm}$, and decreased $(P<0.05)$ over the 3 days following emergence. Surges in FSH concentrations occurred throughout pregnancy, but during the last 30 days of pregnancy the number of surges was reduced and each heifer had one or two ineffective surges (no follicular wave detected). The temporal relationship between FSH surges and emergence of waves was closer $(P<0.01)$ than would be expected if the two events were independent. Surges of FSH occurred rhythmically even when there was no follicular response (no follicle $>5 \mathrm{~mm}$ ). In association with waves in which the largest follicle reached $\geq 10 \mathrm{~mm}$ compared with $6-9 \mathrm{~mm}$, there was greater depression in the FSH nadir, longer intervals from FSH peak to nadir, and longer intervals between adjacent FSH peaks and adjacent waves.
\end{abstract}

\section{Introduction}

The patterns of follicular waves during the bovine oestrous cycle have been well established by transrectal ultrasonographic imaging. A wave of follicles $4-5 \mathrm{~mm}$ in diameter emerges near the day of ovulation, and a second wave (ovulatory wave) emerges 9 or 10 days later (for review, see Ginther et al., 1989a). In some cattle, a third wave is the source of the ovulatory follicle and emerges approximately 16 days after ovulation. Each wave consists of one, and occasionally, two dominant follicles that reach a diameter of approximately $15 \mathrm{~mm}$ and several subordinate follicles, the largest of which reaches a diameter of $7-9 \mathrm{~mm}$. The emergence of a wave is associated with a surge in FSH concentrations (Adams et al., 1992; Sunderland et al., 1994; Gong et al., 1995; Bodensteiner et al., 1996). During early pregnancy, growth of follicles $\geq 2 \mathrm{~mm}$ is similar to growth during the oestrous cycle (Pierson and Ginther, 1986). The wave phenomenon has been studied up to day 70 (Ginther et al., 1989b) and day 100 (Bergfelt et al., 1991) of pregnancy. Waves emerge every 8-10

Received 27 February 1996 days until at least day 100 of pregnancy and in progesteronetreated nonpregnant heifers. The maximum diameter of the dominant follicle of the first wave after ovulation averaged $15-16 \mathrm{~mm}$, and the dominant follicles of subsequent waves averaged $12-14 \mathrm{~mm}$. The wave phenomenon and the temporal associations between wave emergence and changes in FSH concentrations have not been studied after day 100 of pregnancy. However, studies at abattoirs indicated that the diameter of follicles decreased after the third (Rüsse, 1971) or fifth (Rexroad and Casida, 1975) month of pregnancy.

The purpose of the present study was to characterize the temporal associations between follicular waves and circulating concentrations of FSH from day 90 of pregnancy to the emergence of the first postpartum follicular wave.

\section{Materials and Methods}

Animals and ultrasonographic scanning

Eight sexually mature, pregnant, nulliparous Holstein heifers, $1.5-2.5$ years of age, weighing $380-500 \mathrm{~kg}$, were used during 


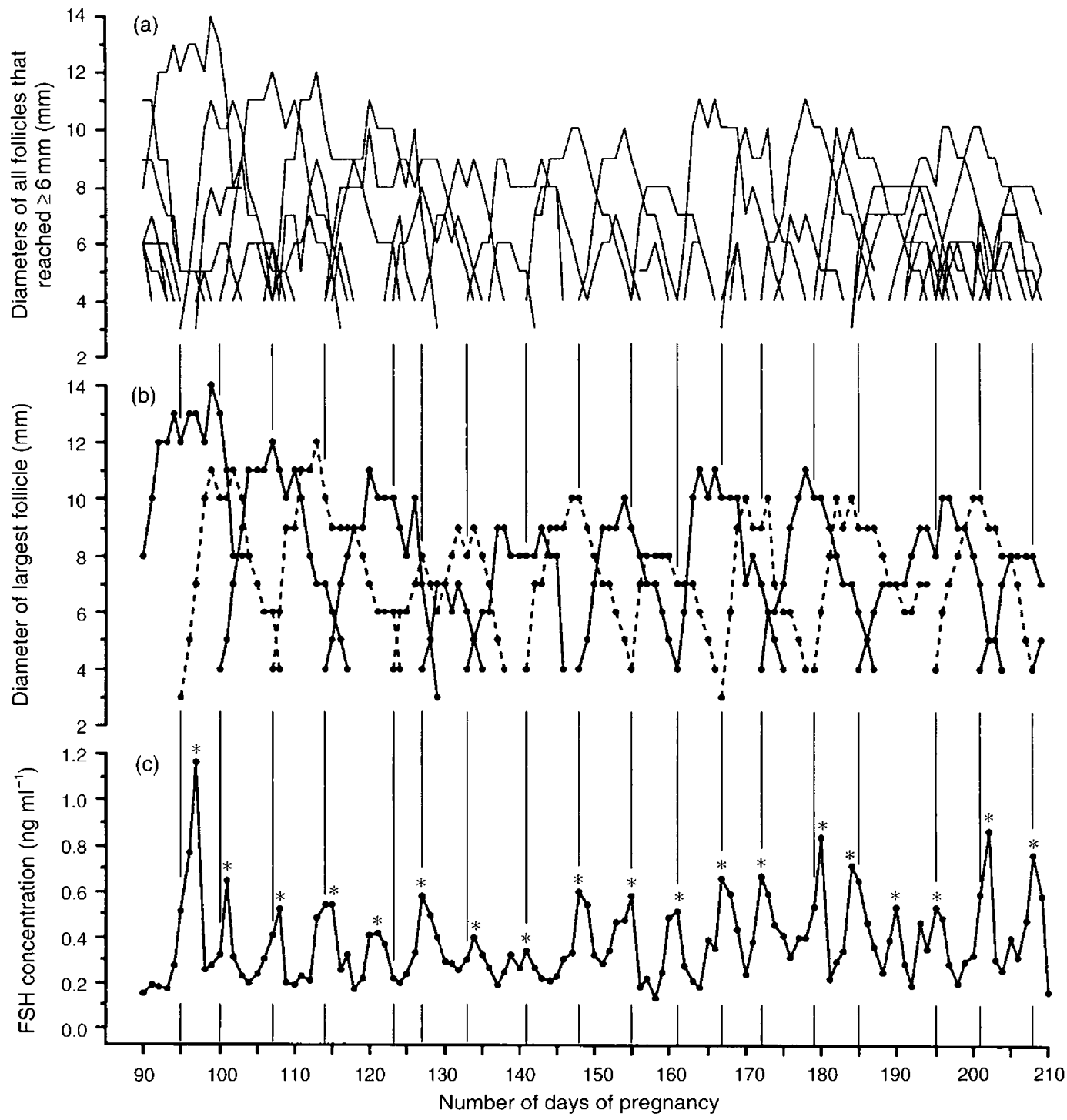

Fig. 1. Data for an individual heifer for months 4-7 of pregnancy showing (a) diameters for all follicles that reached $\geq 6 \mathrm{~mm}$, (b) diameters of the largest follicles that were used to identify waves, and (c) the concentrations of FSH. Vertical lines indicate the days of emergence of follicular waves. *Peaks of FSH surges, as defined with the aid of a cycle-detection program.

June to December. The ovaries were monitored daily by transrectal ultrasonography beginning on day 90 (ovulation = day 0 ) and ending when the largest follicle of the first postpartum wave reached $10 \mathrm{~mm}$. In addition, the follicles of eight similar contemporary nonmated heifers were monitored daily from 3 days before ovulation until emergence of the second follicular wave. Ultrasound examinations were done by a single operator under optimized conditions, as described by Pierson and Ginther (1988). The ultrasound scanner was a real-time, B-mode instrument equipped with a $7.5 \mathrm{MHz}$, lineararray, intrarectal transducer. Individual follicles with antral diameters of $4 \mathrm{~mm}$ or more were identified from day to day, as described by Knopf ef al. (1989). No attempt was made to maintain identity of individual follicles from day to day when the follicles did not attain diameters of $\geq 5 \mathrm{~mm}$.

By definition, a follicular wave was identified by the largest follicle of a group of $\geq 6 \mathrm{~mm}$ follicles emerging on consecutive days, and the largest follicle attaining a diameter greater than the diameter of the nongrowing largest follicle of the previous wave on at least one day (Fig. 1). The day of wave emergence was determined retrospectively as the last day on which the largest follicle was $4 \mathrm{~mm}$ before growing to $\geq 6 \mathrm{~mm}$. The number of $\geq 6 \mathrm{~mm}$ follicles in a wave was based on emergence of the follicles on the same or consecutive days from emergence of the largest follicle. Follicles reaching $\geq 6 \mathrm{~mm}$ but not emerging on a consecutive day from emergence of the follicles of an identified wave were designated as nonwave follicles.

\section{Assay of FSH}

Blood was collected by coxygeal venepuncture into heparinized tubes immediately before ultrasonic scanning each day from day 90 to the postpartum follicular wave. Blood was 
stored immediately on ice until centrifugation (1000 $\mathrm{g}$ for $15 \mathrm{~min})$; plasma was stored frozen $\left(-20^{\circ} \mathrm{C}\right)$. FSH concentrations were determined by a solid-phase radioimmunoassay validated in our laboratories and described by Bodensteiner et al. (1996). All samples for each heifer were measured in a separate assay, using five heifers in which complete follicular data were successfully obtained and one heifer in which only one isolated wave was detected after day 107. The mean intraand interassay coefficients of variation were 14.7 and $17.4 \%$, respectively, for a quality control sample with an average FSH concentration of $0.62 \mathrm{ng} \mathrm{ml}^{-1}$.

A technique that was developed to study episodic fluctuations in concentrations of circulating hormones (Clifton and Steiner, 1983) was used to identify peaks in the concentrations of FSH in individual heifers. This procedure has been used to detect FSH fluctuations in blood samples in other species (Materri et al., 1992; Bergfelt and Ginther, 1993; Ginther et al., 1995). The programme determines threshold concentrations of FSH based on the variability of the assay results among triplicate samples for each heifer within each day. Concentrations that were greater than the threshold values were detected and identified as the peak FSH concentration of a fluctuation. In the present study, a fluctuation identified by the cycle-detection programme was defined as an FSH surge if the fluctuation encompassed more than one day, as indicated by more than one increasing value before the peak or more than one decreasing value after the peak.

\section{Statistical analyses}

The data on the follicles were combined for the two ovaries for study of the systemic interrelationships between follicles and circulating FSH. The hypothesis that follicles emerge in groups (waves) rather than at random was tested by applying a chi-square goodness-of-fit analysis to the observed and expected number of days with the emergence of $0,1,2$ and $\geq 3$ follicles that later attained $\geq 6 \mathrm{~mm}$ (Table 1; Ginther and Kot, 1994). The expected number was calculated according to the Poisson random variable (Sokal and Rohlf, 1969). The analyses were made separately for each heifer during pregnancy only and extended from day 90 of pregnancy to 6 days after the emergence of the last follicle that reached $\geq 6 \mathrm{~mm}$.

Wave 1 of the nonmated heifers and the first wave after day 90 of pregnancy were compared by unpaired $t$ tests for the end points shown in Table 2. In addition, the characteristics of the first four waves after day 90 were compared by analyses of variance for sequential data for the same end points. In these and other analyses, the analysis of variance was followed by Duncan's multiple range test to detect differences among means; paired $t$ tests were also used for selected comparisons.

Pregnancy was divided into increments of 30 days that were defined as months as follows: month 4, days 90-119; month 5 , days 120-149; month 6 , days 150-179; month 7 , days 180-209; month 8, days 210-239; month 9, days 240-269. Each follicular wave with follicles $\geq 6 \mathrm{~mm}$ was assigned to the month in which the largest follicle emerged as a $4 \mathrm{~mm}$ follicle. For each follicular end point (Table 3), the mean for all follicles or all waves in a given month for a given heifer was used in the analyses as a single value per month; the degrees of freedom
Table 1. Number of days on which $0,1,2$ or $\geq 3$ follicles emerged that later reached $\geq 6 \mathrm{~mm}$ in diameter

\begin{tabular}{lccccc}
\hline \multirow{2}{*}{$\begin{array}{l}\text { Heifer } \\
\text { number }\end{array}$} & Observed & \multicolumn{4}{c}{ Number of follicles emerging on a day } \\
\cline { 3 - 6 } & Expected* & 0 & 1 & 2 & 3 \\
\hline \multirow{2}{*}{1} & & & & & \\
\hline \multirow{2}{*}{2} & Observed & 78 & 27 & 9 & 6 \\
& Expected & 69 & 39 & 11 & 2 \\
3 & Observed & 109 & 34 & 19 & 11 \\
& Expected & 92 & 58 & 18 & 5 \\
4 & Observed & 125 & 30 & 17 & 2 \\
& Expected & 116 & 47 & 9 & 1 \\
5 & Observed & 117 & 27 & 22 & 5 \\
& Expected & 102 & 53 & 14 & 3 \\
6 & Observed & 112 & 23 & 8 & 7 \\
& Expected & 97 & 42 & 9 & 2 \\
7 & Observed & 116 & 36 & 12 & 9 \\
& Expected & 102 & 54 & 14 & 3 \\
& Observed & 130 & 35 & 12 & 9 \\
& Expected & 115 & 55 & 13 & 2 \\
\hline
\end{tabular}

*Derived from the Poisson distribution, as described by Sokal and Rohlf (1969). Significant difference $(P<0.005)$ for each heifer between observed and expected for number of days with $0,1,2$, and $\geq 3$ follicles.

for these comparisons were based on the number of heifers. Differences among the 6 months in the number of events per month averaged over the heifers were tested by analyses of variance for sequential data. In addition to the analyses for months 4-9, data for numbers of follicles were compared between the second-last and last months of pregnancy by paired $t$ tests. A linear regression analysis was carried out for each heifer to characterize the changes in maximal diameter of the largest follicle for sequential waves and changes in the duration of the interwave interval.

The association between emergence of follicular waves and concentrations of FSH was studied by normalizing the FSH values to the day of wave emergence. The FSH values for 3 days before, the day of, and 3 days after emergence were averaged for each day over all waves. The averages for each heifer and day were then used as the end point for determining whether there were differences among months in the FSH profile centered on the day of wave emergence. This was done with a day-by-month analysis of variance.

The FSH peaks identified by the cycle-detection programme were compared among months, as described for the follicles, using the end points shown in Table 3. Combined for five heifers with complete data, the FSH concentrations at the peak and at the nadir after the peak of the FSH surge associated with the emergence of a wave and the interpeak and interwave intervals were compared by analyses of variance between the waves with largest follicle $10-1.4 \mathrm{~mm}(\geq 10 \mathrm{~mm})$ versus 6-9 $\mathrm{mm}$. The diameter of $10 \mathrm{~mm}$ was chosen because the dominant follicle reaches $\geq 10 \mathrm{~mm}$ during the oestrous cycle (Ginther et al., 1989a). The FSH concentrations for 5 days after the peak normalized to the day of wave emergence were compared between the two follicle groups by a day-by-group analysis of variance. Spearman's correlations or linear regression analyses were performed on various combinations of 
Table 2. Comparisons (means \pm SEM) of the first wave after ovulation in eight nonmated heifers with the first four waves after day 90 in seven pregnant heifers

\begin{tabular}{|c|c|c|c|c|c|}
\hline \multirow[b]{2}{*}{ End point } & \multirow{2}{*}{$\begin{array}{c}\text { Wave } 1 \text { of } \\
\text { nonmated } \\
\text { heifers }\end{array}$} & \multicolumn{4}{|c|}{ Sequential waves after day 90 in pregnant heifers } \\
\hline & & First & Second & Third & Fourth \\
\hline \multicolumn{6}{|l|}{ Largest follicle } \\
\hline Maximum diameter & $16.0 \pm 0.3^{X Y}$ & $12.7 \pm 0.5^{Y a}$ & $11.4 \pm 0.3^{b c}$ & $10.3 \pm 0.6^{c}$ & $10.4 \pm 0.9^{c}$ \\
\hline Number of days to maximum diameter & $7.0 \pm 0.5$ & $7.0 \pm 0.6$ & $7.3 \pm 1.0$ & $5.1 \pm 1.4$ & $5.1 \pm 1.0$ \\
\hline Number of days follicle was largest & $14.5 \pm 1.2^{x}$ & $6.3 \pm 2.3^{\Upsilon}$ & $6.6 \pm 1.0$ & $4.9 \pm 1.0$ & $5.9 \pm 0.6$ \\
\hline \multicolumn{6}{|l|}{ Second largest follicle } \\
\hline Maximum diameter & $7.9 \pm 0.4$ & $7.0 \pm 0.6$ & $8.2 \pm 0.5$ & $7.8 \pm 0.5$ & $8.0 \pm 0.6$ \\
\hline \multicolumn{6}{|l|}{ Number of $\geq 6 \mathrm{~mm}$ follicles } \\
\hline In a wave & $5.2 \pm 0.6$ & $6.0 \pm 0.6^{\mathrm{a}}$ & $4.4 \pm 0.9^{\mathrm{ab}}$ & $2.7 \pm 0.6^{b}$ & $2.7 \pm 0.4^{b}$ \\
\hline Between waves & $0.1 \pm 0.1$ & $0.3 \pm 0.3$ & $1.6 \pm 0.6$ & $0.7 \pm 0.4$ & $0.7 \pm 0.4$ \\
\hline \multicolumn{6}{|l|}{ Number of days for emergence of all } \\
\hline follicles of a wave & $2.4 \pm 0.3$ & $2.3 \pm 0.3$ & $2.1 \pm 0.4$ & $2.1 \pm 0.5$ & $1.7 \pm 0.4$ \\
\hline Interwave interval (days) & $9.5 \pm 0.3$ & $8.4 \pm 0.9$ & $7.7 \pm 1.1$ & $7.7 \pm 0.6$ & $8.3 \pm 0.5$ \\
\hline
\end{tabular}

${ }^{x y}$ Means within a row that differ significantly $(P<0.05)$ between the first wave in nonbred heifers and the first wave after day 90 in pregnant heifers.

Means for the first four waves after day 90 with no common superscript letters are significantly different $(P<0.05)$.

Table 3. Means ( \pm SEM) for follicular and FSH end points for months $4-9$ in pregnant heifers

\begin{tabular}{|c|c|c|c|c|c|c|c|c|}
\hline \multirow[b]{2}{*}{ End point } & \multicolumn{6}{|c|}{ Month of pregnancy } & \multirow{2}{*}{$\begin{array}{l}\text { Mean } \\
\text { SEM }\end{array}$} & \multirow[b]{2}{*}{ Probability } \\
\hline & 4 & 5 & 6 & 7 & 8 & 9 & & \\
\hline \multicolumn{9}{|l|}{ Follicles } \\
\hline \multicolumn{9}{|l|}{ Number of follicles per heifer per month } \\
\hline Reaching $5 \mathrm{~mm}$ only & $10.4^{\mathfrak{a}}$ & $12.9^{a}$ & $12.0^{\mathrm{a}}$ & $13.2^{a}$ & $13.5^{3}$ & $4.9^{b}$ & \pm 1.8 & $<0.07$ \\
\hline Reaching $\geq 6 \mathrm{~mm}$ & $15.6^{\mathrm{a}}$ & $13.6^{\mathrm{a}}$ & $15.6^{\mathrm{a}}$ & $21.0^{\mathrm{b}}$ & $15.0^{\mathrm{a}}$ & $6.6^{c}$ & \pm 1.8 & $<0.0004$ \\
\hline Reaching $\geq 8 \mathrm{~mm}$ & $6.3^{\mathrm{a}}$ & $4.4^{\mathrm{a}}$ & $5 . I^{\mathrm{a}}$ & $6.0^{\mathrm{a}}$ & $4.8^{\mathrm{a}}$ & $2.2^{\mathrm{b}}$ & \pm 0.6 & $<0.0008$ \\
\hline Reaching $\geq 10 \mathrm{~mm}$ & $3.3^{\mathrm{a}}$ & $1.9^{\mathrm{b}}$ & $2.4^{\mathrm{ab}}$ & $2.4^{\mathrm{ab}}$ & $1.7^{\mathrm{bc}}$ & $0.6^{c}$ & \pm 0.5 & $<0.002$ \\
\hline \multicolumn{9}{|l|}{ Number of days with no emerging } \\
\hline$\geq 6 \mathrm{~mm}$ follicle & $20.4^{\mathrm{a}}$ & $20.6^{\mathrm{a}}$ & $20.3^{a}$ & $18.4^{\mathrm{a}}$ & $20.7^{\mathrm{a}}$ & $25.8^{\mathrm{b}}$ & \pm 0.8 & $<0.0001$ \\
\hline \multicolumn{9}{|l|}{ Follicular waves } \\
\hline Number of waves & $3.4^{\mathrm{bc}}$ & $4.1^{3 b}$ & $4.4^{\mathrm{a}}$ & $4.1^{\mathrm{ab}}$ & $4.7^{\mathrm{a}}$ & $2.6^{\mathrm{c}}$ & \pm 0.3 & $<0.0008$ \\
\hline Maximum diameter largest follicle $(\mathrm{mm})$ & $11.1^{\mathrm{a}}$ & $9.5^{\mathrm{b}}$ & $9.5^{\mathrm{b}}$ & $9.6^{6}$ & $9.1^{\mathrm{b}}$ & $8.5^{\mathrm{b}}$ & \pm 0.4 & $<0.0002$ \\
\hline Maximum diameter second largest follicle $(\mathrm{mm})$ & $8.0^{\mathrm{a}}$ & $6.9^{\mathrm{b}}$ & $6.9^{b}$ & $6.9^{b}$ & $6.8^{\mathrm{b}}$ & $6.5^{\mathrm{b}}$ & \pm 0.2 & $<0.0001$ \\
\hline Interwave interval (days) & $8.1^{x}$ & $6.6^{\mathrm{Y}}$ & 7.3 & 6.4 & 6.5 & 6.3 & \pm 0.6 & $<0.16$ \\
\hline Number of follicles $\geq 6 \mathrm{~mm}$ in a wave & $3.7^{\mathrm{ab}}$ & $2.5^{\mathrm{cd}}$ & $3.3^{\mathrm{abc}}$ & $4.0^{a}$ & $2.8^{\mathrm{bcd}}$ & $1.8^{\mathrm{d}}$ & \pm 0.4 & $<0.002$ \\
\hline Number of follicles $\geq 6 \mathrm{~mm}$ between adjacent waves & 0.9 & 0.7 & 0.6 & 1.0 & 0.5 & 0.2 & \pm 0.2 & $<0.15$ \\
\hline \multicolumn{9}{|l|}{$\mathrm{FSH}$} \\
\hline Number of defined surges & 4.4 & 5.0 & 5.2 & 5.4 & 4.6 & 3.6 & \pm 0.5 & $<0.21$ \\
\hline Interpeak interval (days) & $6.4^{\mathrm{a}}$ & $6.1^{\mathrm{a}}$ & $5.6^{\mathrm{a}}$ & $5.9^{\mathrm{a}}$ & $6.5^{\mathrm{a}}$ & $10.6^{\mathrm{b}}$ & \pm 0.6 & $<0.001$ \\
\hline Concentration at peak ( $\mathrm{ng} \mathrm{ml}^{-\mathrm{I}}$ ) & $0.79^{a}$ & $0.74^{\mathrm{a}}$ & $0.89^{\mathrm{ab}}$ & $1.02^{b}$ & $1.01^{\mathrm{b}}$ & $0.91^{\mathrm{ab}}$ & \pm 0.15 & $<0.018$ \\
\hline Concentration at nadir $\left(\mathrm{ng} \mathrm{ml}^{-1}\right)$ & 0.30 & 0.30 & 0.40 & 0.41 & 0.43 & 0.41 & \pm 0.10 & $<0.10$ \\
\hline Average concentration (ng ml-1) & $0.46^{\mathrm{a}}$ & $0.52^{\mathrm{ab}}$ & $0.60^{\mathrm{b}}$ & $0.67^{\mathrm{b}}$ & $0.66^{b}$ & $0.64^{b}$ & \pm 0.13 & $<0.013$ \\
\hline
\end{tabular}

alcid Means within a row with no common superscripts are significantly different $(P<0.05)$ by a multiple range test.

${ }^{X Y}$ Means that are different $(P<0.05)$ by a paired $t$ test.

diameter of largest follicle, duration of interwave interval, duration of interpeak interval, and concentrations of $\mathrm{FSH}$ at the peak and nadir.

The extent of temporality between day of emergence of a follicular wave and the peak value of an FSH surge involves the shortest interval (days) between the two events. The procedure described by Ginther et al. (1995) was used to determine whether the two discrete events occurred independently of each other. The expected temporality was calculated separately for each interval by calculating the average number of days between an FSH peak value and the nearest wave emergence if each day of wave emergence had equal probability of falling on any day between FSH peaks. The expected was compared with the observed for the corresponding peak-to-peak interval by 
univariate $t$ tests. The null hypothesis was that the difference between the expected day of occurrence and the observed day of occurrence was zero.

The following comparisons were made by paired $t$ tests for the period extending from 10 days before parturition to the day the largest follicle of the postpartum wave reached $10 \mathrm{~mm}$ : (1) peak FSH value of postpartum FSH surge compared with the average peak value during pregnancy; and (2) mean daily FSH concentrations over the six months of pregnancy compared with the mean for 10 days before parturition.

\section{Results}

Both ovaries were located each day from the beginning to the end of the study in all heifers, with the exception that in two heifers the ovaries were frequently not found from days 210 and 240 , respectively. Data collection was discontinued in these two heifers beginning on the day that locating difficulties began; however, the ovaries were found again beginning on the day of parturition, and the data from parturition to emergence of the first postpartum wave were included in the analyses. FSH was not assayed in the two heifers with missing follicle information. In another heifer, the ovaries were found each day, but no emerging follicles that reached $>5 \mathrm{~mm}$ were detected after day 107, except for an isolated $9 \mathrm{~mm}$ follicle emerging at day 238. Follicular and FSH data for this heifer were handled separately. Seven heifers, therefore, were available for the analyses of follicle data during pregnancy, six heifers for the peripartum analyses of FSH data, and five heifers for study of the associations between follicle and FSH data. Parturition occurred on a mean of 277 days (SD \pm 8 days; range: 258-285 days). In one heifer, parturition occurred before the end of month 9, but the data for this month for this heifer were not included in the analyses because of the failure to find the ovaries.

In each of seven heifers, the observed number of follicles emerging each day and reaching $\geq 6 \mathrm{~mm}$ differed $(P<0.005)$ from the number expected to emerge per day under random conditions (Table 1). That is, the null hypothesis of a random number of events per day, according to the Poisson random variable, was rejected. The observed number of days with one follicle emerging was less than expected for the Poisson random distribution, and the observed number of days with $\geq 3$ follicles emerging was greater than expected in each heifer.

The comparisons of characteristics of the first postovulatory wave in nonmated heifers with the first wave after day 90 in pregnant heifers and the characteristics of the first four waves after day 90 are shown (Table 2). Significant differences among months 4-9 were obtained for most end points involving number of follicles and characteristics of the follicular waves (Table 3). In addition, the last month of pregnancy, compared with the second-last month, had fewer $(P<0.05)$ follicles emerging that reached $5 \mathrm{~mm}(1.6 \pm 0.7$ versus $10.2 \pm 2.4)$, $\geq 6 \mathrm{~mm}(3.8 \pm 1.4$ versus $13.0 \pm 2.0)$ and $\geq 8 \mathrm{~mm}(1.0 \pm 0.4$ versus $4.8 \pm 0.7)$. The regression analyses for changes in maximum diameter of the largest follicle per wave showed a linear decline $(P<0.0001)$ as pregnancy progressed when data for the seven heifers were grouped. Regression analyses for individual heifers showed a linear decline $(P<0.007)$ for five of the seven heifers. Regression analyses for the interwave interval also showed a linear decline $(P<0.001)$ when all heifers were grouped but not for individual heifers.

The growth and atresia profiles of the largest follicle of waves showed significant day and month effects and a day-bymonth interaction when the seven heifers with follicular data were used and when only the five heifers with FSH as well as follicular data were used (Fig. 2). The interactions resulted primarily from a more prominent mean profile for month 4 and a less prominent profile for month 9; prominence was shown by a more prolonged presence and greater attained diameter for the largest follicle. The profiles for the intervening months were intermediate and did not differ from one another when only months 5-8 were analysed. The profile of the FSH concentrations from 3 days before to 3 days after emergence of a follicular wave did not differ among months (Fig. 2). Averaged over all months, FSH concentrations reached peak values on the day of wave emergence.

For identified FSH surges, the differences among months are shown (Table 3). The effects of grouping follicular waves according to maximum diameter of the largest follicle on the interwave, interpeak, and peak-to-nadir intervals and on the characteristics of the associated FSH surge are shown (Table 4). The results of the correlation analyses were as follows: (1) diameter of largest follicle versus length of the interwave interval $(r=+0.39$; $P<0.0001)$; (2) diameter of largest follicle versus length of the FSH interpeak interval $(r=+0.45$; $P<0.0001$ ), duration of interwave interval versus duration of FSH interpeak interval $(r=+0.47 ; P<0.0001)$, diameter of largest follicle versus FSH concentration at the nadir $(r=-0.30 ; P<0.001)$, and diameter of largest follicle versus FSH concentration at the peak $(r=-0.08 ; P<0.4)$. The linear regression of the FSH peak concentration on the diameter of largest follicle was not significant. The FSH profiles normalized to the day of wave emergence for waves with the largest follicle $\geq 10 \mathrm{~mm}$ versus $6-9 \mathrm{~mm}$ are shown (Fig. 3). There was a main effect of day averaged over the two follicle groups and a tendency for an interaction of day-by-group $(P<0.08)$ but no main effect of group. The interaction seemed primarily the result of lower FSH concentrations 3-4 days after wave emergence in the group with $\geq 10 \mathrm{~mm}$ follicles. The FSH profiles are shown for months $4-7$ for the heifer that had only one follicular wave after day 107 (Fig. 4).

The mean number of days from the peak of an FSH surge to emergence of a follicular wave (0.5-1.2 days for the five heifers) was shorter for each heifer averaged over all months $(P<0.05)$ and for each month averaged over all heifers $(P<0.04)$ than for the expected number of days, as calculated from the Poisson random distribution (1.5-1.7 days for the five heifers). Follicular and FSH profiles are shown (Fig. 1) for months $4-7$ for the heifer with the closest temporality between the two events (highest probability for a difference between observed and expected).

The mean FSH value for the last 10 days of pregnancy $\left(0.45 \pm 0.1 \mathrm{ng} \mathrm{ml}^{-1}\right)$ was less $(P<0.03)$ than for the mean value over the six months of pregnancy $\left(0.59 \pm 0.1 \mathrm{ng} \mathrm{ml}^{-1}\right)$. The number of FSH surges during the last 30 days $(3.2 \pm 0.6)$ was greater $(P<0.0001)$ than the number of emerging waves $(2.2 \pm 0.6)$. The interval from the last peak of an FSH surge to parturition was $11.8 \pm 3.1$ days and the interval from 


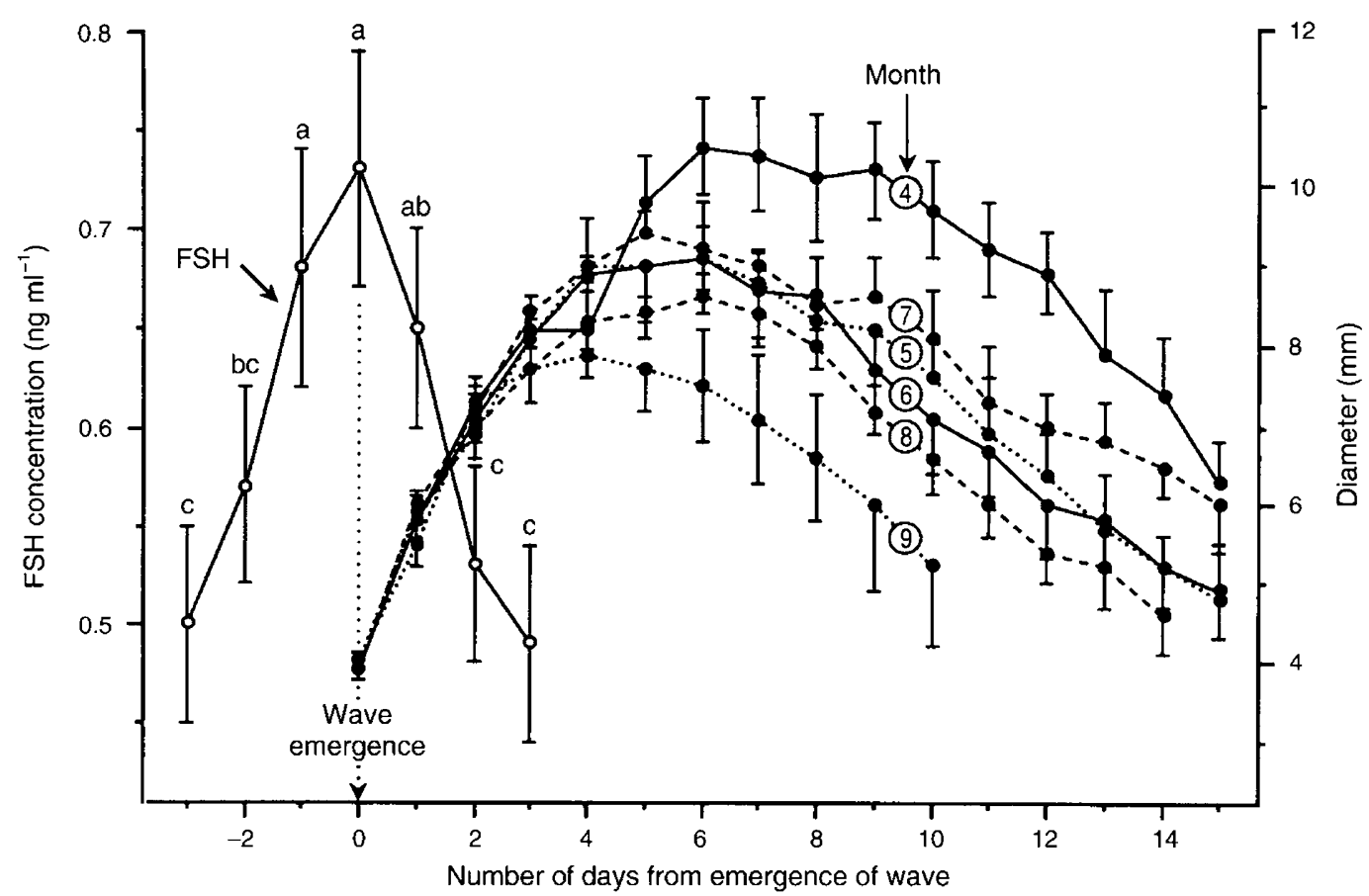

Fig. 2. Diameter (mean \pm SEM) profiles for largest follicle of waves during months 4-9 of pregnancy for five heifers normalized to the day of wave emergence $(-)$ and the associated FSH concentration (mean \pm SEM) averaged over all waves $(O)$. For the follicular waves, the day effect $(P<0.0001)$, month effect $(P<0.005)$, and the interaction $(P<0.0001)$ were significant. For the FSH concentrations, the day effect was significant $(P<0.001)$ but the month effect and interaction were not; months were combined ( $n=120$ waves) and the means that are significantly different $(P<0.05)$ are indicated by different superscripts.

Table 4. Means ( \pm SEM) for effect of diameter of largest follicle on the interwave interval and FSH surges during months $4-9$ in pregnant heifers

\begin{tabular}{|c|c|c|c|c|}
\hline \multirow{3}{*}{$\begin{array}{l}\text { End point } \\
\text { Interwave interval (days) }\end{array}$} & \multicolumn{4}{|c|}{ Diameter of largest follicle* } \\
\hline & $\geq 10 \mathrm{~mm}^{+}$ & $6-9 \mathrm{~mm}^{+}$ & \multicolumn{2}{|r|}{$\geq 5 \mathrm{~mm}^{+\dagger}$} \\
\hline & $7.4 \pm 0.2(67)^{\mathrm{a}}$ & $5.9 \pm 0.2(43)^{\mathrm{b}}$ & & - \\
\hline \multicolumn{5}{|l|}{ FSH surge } \\
\hline Interpeak interval (days) & $7.1 \pm 0.2(61)^{\mathrm{a}}$ & $5.5 \pm 0.2(41)^{\mathrm{b}}$ & 5.5 & $\pm 0.2(24)^{\mathrm{b}}$ \\
\hline Peak-to-nadir interval (days) & $3.4 \pm 0.2(60)^{\mathrm{a}}$ & $2.5 \pm 0.2(42)^{\mathrm{b}}$ & 2.1 & $\pm 0.2(25)^{\mathrm{b}}$ \\
\hline Peak concentration $\left(\mathrm{ng} \mathrm{ml}^{-1}\right.$ ) & $0.88 \pm 0.06(65)$ & $0.90 \pm 0.05(40)$ & & - \\
\hline Nadir concentration $\left(\mathrm{ng} \mathrm{ml}^{-1}\right.$ ) & $0.34 \pm 0.03(67)^{a}$ & $0.46 \pm 0.04(40)^{\mathrm{b}}$ & & - \\
\hline
\end{tabular}

${ }^{\mathrm{ab}}$ Means within a row with different superscripts are significantly different $(P<0.001)$. Number in parentheses is number of available observations.

* Largest follicle of the wave that emerged in association with the analysed FSH surge.

"Data are from five heifers with complete follicular and FSH data, except for an occasional missing FSH value.

${ }^{\ddagger+}$ Data are from one heifer with 26 consecutive FSH surges without an associated wave with the largest follicle $>5 \mathrm{~mm}$.

emergence of the last follicular wave to parturition was $21.6 \pm 2.4$ days.

The average peak value for the postpartum FSH surge ( $\left.1.9 \pm 0.5 \mathrm{ng} \mathrm{ml}^{-1}\right)$ was greater $(P<0.04)$ than for the average of all peaks during pregnancy $\left(0.9 \pm 0.2 \mathrm{ng} \mathrm{ml}^{-1}\right)$. The interval from parturition to the emergence of the first postpartum wave averaged $4.0 \pm 0.9$ days (range, 2-7 days). No nonwave follicles of $6 \mathrm{~mm}$ diameter were detected between the day of parturition and the day of wave emergence. The postpartum wave contained $5.9 \pm 0.7$ follicles $\geq 6 \mathrm{~mm}$, which was greater
$(P<0.05)$ than for each month of pregnancy. Emergence encompassed 2 days for all eight heifers.

\section{Discussion}

In each of seven pregnant heifers, follicles reaching a diameter $\geq 6 \mathrm{~mm}$ emerged in groups or waves rather than randomly. On the basis of previous studies to day 70 (Ginther et al., 1989b) and day 100 (Bergfelt et al., 1991) of pregnancy 


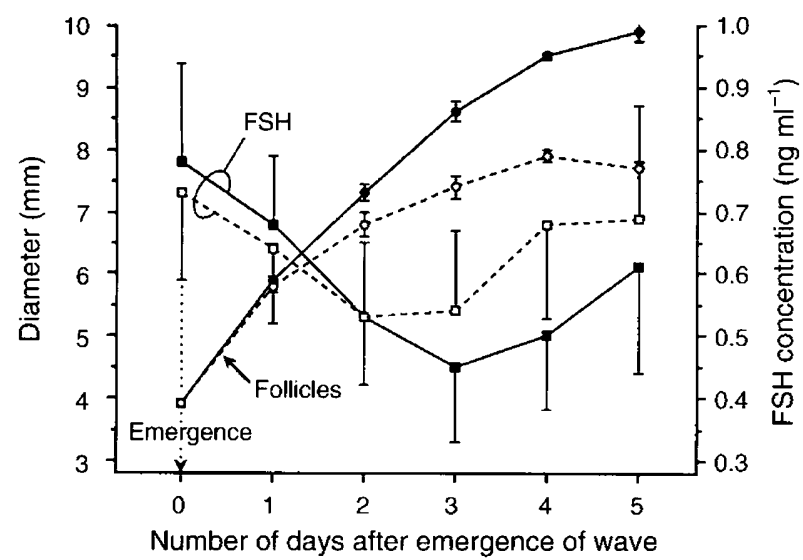

Fig. 3. Mean ( \pm SEM) diameter of largest follicle normalized to the day of emergence for 67 waves with largest follicle $\geq 10 \mathrm{~mm}(-)$ and for 42 waves with largest follicle $6-9 \mathrm{~mm}(O)$ in pregnant heifers from day 90 of pregnancy to the first postpartum follicular wave. FSH concentrations (mean $\pm \mathrm{SEM}$ ) for the two groups of waves are shown ( $\geq 10 \mathrm{~mm}, \boldsymbol{\square} ; 6-9 \mathrm{~mm}, \square$ ). The day effect for FSH concentrations was significant $(P<0.0001)$ and the day-by-group interaction tended to be, but was not, significant $(P<0.07)$.

together with the results of the present study, it is concluded that the formation of follicular waves occurs throughout pregnancy in most heifers, except for an average of 3 weeks before parturition. The characteristics of the waves were not constant, however. Previous studies (Ginther et al., 1989b; Bergfelt et al., 1991) demonstrated that the maximum diameter of the dominant follicle for wave 1, after ovulation, was greater than for all subsequent waves up to day 100. Similarly, in the present study, the dominant follicle of wave $I$ in nonmated heifers was larger than for the first wave emerging after day 90 . In a previous experiment (Bergfelt et al., 1991), the maximum diameter of the largest follicle beginning at the second wave after ovulation and extending to day 100 (range of means, $12.4-13.0 \mathrm{~mm}$ ) and the duration of the interwave interval (range of means, 8.5-9.6 days) were constant (not significantly different) and are similar to the means for the first wave after day 90 in the present study (largest follicle, $12.7 \mathrm{~mm}$; interwave interval, 8.4 days).

A transitional period of decreasing follicular activity occurred over the first three waves following day 90 or between months 4 and 5 , as indicated by decreased diameters and number of follicles, decreased duration of interwave intervals, and increased numbers of waves; that is, the waves became more frequent but were less prominent. A minority (18\%) of the intervals during the last 6 months of pregnancy were equivalent to the duration of intervals between emergence of wave 1 and wave 2 ( 9 and 10 days) in the nonmated heifers. In pregnant heifers, many $(41 \%)$ of the 9 and 10 day intervals occurred during month 4 . Most $(66 \%)$ intervals were of 4-7 days duration and these occurred mainly after month 4 . The declining linear regressions between day 90 and the last detected follicle $\geq 6 \mathrm{~mm}$ indicated a gradual decrease, on average, in maximum diameter of the largest follicle and duration of the interwave interval. The comparisons of monthly means, however, indicated that the greatest decline in follicular activity occurred between months 4 and 5. These findings confirm reports of decreasing follicle diameters after the third (Rüsse, 1971) or fifth (Rexroad and Casida, 1975) month and are in agreement with a recent report (Dominguez, 1995) from data obtained from an abattoir that the number of medium $(5-9 \mathrm{~mm})$ follicles was reduced during the third trimester and the number of large $(\geq 10 \mathrm{~mm})$ follicles was reduced during the last two trimesters.

The decrease in the diameter of largest follicle after the first wave after day 90 could reflect a decrease in LH pulse frequency and average $\mathrm{LH}$ concentrations. Schallenberger ef al. (1985) measured pulsatile secretory patterns of several hormones by sampling every $20 \mathrm{~min}$ for $12 \mathrm{~h}$ on one day of each month of pregnancy. Changes in the concentrations of FSH (basal and pulse frequencies) were not detected under these conditions of sampling. However, the lowest LH pulse frequencies and the lowest average LH concentrations occurred in the samples taken at approximately days 92 and 122. The experimental suppression of pulsatile secretion of $\mathrm{LH}$ reportedly blocks the development of dominant follicles after they reach a diameter of approximately $9 \mathrm{~mm}$ during the oestrous cycle (Gong et al., 1995). In the present study, the mean diameter of the largest follicle during month 5 (days 120-149) and, thereafter, was $9.6 \mathrm{~mm}$ or less compared with $11.1 \mathrm{~mm}$ during month 4 (days 90-119). The reason for the transient increase in number of follicles per wave during month 7 is not known.

Mean numbers of follicles per month for all diameters gradually declined from month 7 to month 9 , as did the number of follicles $\geq 6 \mathrm{~mm}$ within a wave and between waves and number of days with emergence of follicles that reached $\geq 6 \mathrm{~mm}$. The reduced follicular activity during month 9 (days 240-269) or during the 30 days before parturition was marked. There was a sharp decline $(45-63 \%)$ between months 8 and 9 in the number of follicles reaching $\geq 5 \mathrm{~mm}$ and $\geq 6 \mathrm{~mm}$ and the number of waves. On average, no follicles emerged during the last 21 days of pregnancy that reached $\geq 6 \mathrm{~mm}$. Perhaps the diminished follicular and FSH activity near the end of pregnancy was related to high concentrations of oestrogens at that time. Oestrogens (oestradiol and oestrone) increase gradually on day 122 (mean) with a sharp increase on day 275 (mean) (Schallenberger et al., 1985).

Averaged over all follicular waves, the profile for mean concentrations of FSH normalized to emergence of a follicular wave was distinctive during months 4-9 of pregnancy. Concentrations increased over the 3 days before emergence, reached a peak on the day of emergence when the future dominant follicle was $4 \mathrm{~mm}$, and declined over the 3 days following emergence. Similar results have been reported for the follicle-FSH relationship during the oestrous cycles of cattle (Adams et al., 1992), horses (Bergfelt and Ginther, 1993; Ginther and Bergfelt, 1993), and sheep (Ginther et al., 1995); during the prepubertal period in cattle (Adams et al., 1994) and during early pregnancy in horses (Ginther and Bergfelt, 1992). The close relationship between increasing FSH concentrations and emergence of waves was shown also by the agreement between the mean FSH interpeak interval of identified surges (6.8 days), and the mean interwave interval (6.9 days). In addition, the temporal relationship between the day of a statistically identified peak of an FSH surge and the day of the nearest defined emergence of a follicular wave was close. In a 


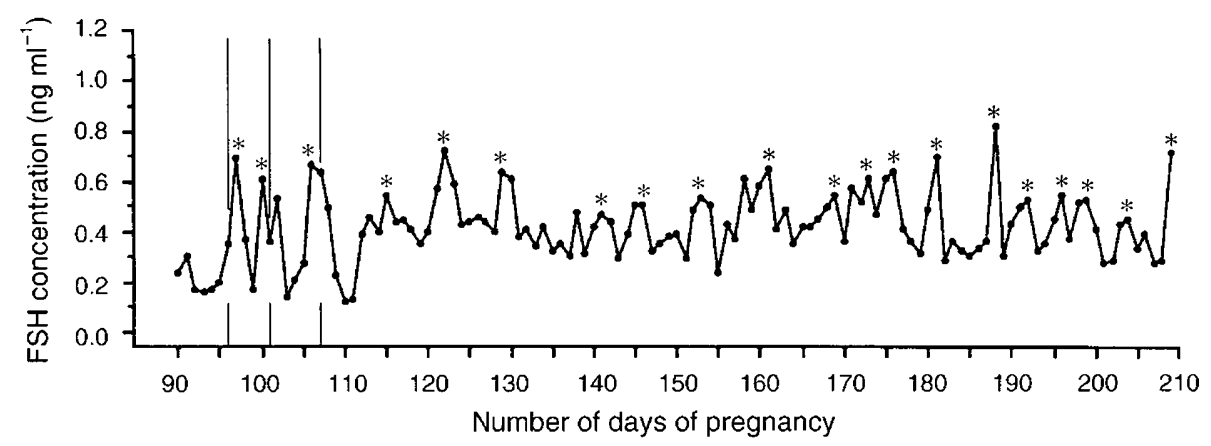

Fig. 4. Data for FSH concentrations during months 4-7 of pregnancy in a heifer that initially (days 90-110) had three follicular waves (days of emergence shown by vertical lines) but no detected waves, thereafter. *Peaks of detected FSH surges. Note the lower nadirs in the FSH surges associated with the stimulation of follicular waves with a large follicle ( $\geq 10 \mathrm{~mm}$ ).

total of 118 follicular waves with an associated FSH surge, emergence occurred within $I$ day of the peak of the surge in 98 waves $(83 \%)$. There were only four waves $(3 \%)$ without an associated FSH surge. These data indicate that almost all waves were accounted for by a detected temporally related FSH surge.

A follicular wave did not emerge in association with the peak of 25 of $143(17 \%)$ FSH surges. In four of $25(16 \%)$ surges unaccompanied by a follicular wave, the surge was closely associated with a follicle $\geq 6 \mathrm{~mm}$ in diameter that emerged between waves (for example, Fig. 1, day 190); that is, occasionally an FSH surge stimulated emergence of follicles that did not meet the definition of a wave. In six of $25(24 \%)$, two surges seemed to be associated with the same follicular wave. Fifteen of $25(60 \%)$ surges or $10 \%$ of the total number of surges were unaccompanied by a follicular wave (no follicle emerged that reached $\geq 6 \mathrm{~mm}$ ) and most of these (10 of $15,67 \%$ ) occurred after day 243 . The presence of FSH surges without an apparent follicular response during the last 30 days was shown by the greater number of surges than waves and the shorter interval from last surge to parturition than from the last wave to parturition. In this regard, all five heifers had one or two FSH surges near the end of pregnancy that were not associated with emergence of a detected follicle.

The following findings indicate average monthly FSH differences: (1) mean FSH concentration was less for month 4 than for months 6-9; (2) concentrations at the nadir between surges tended to be less for months 4 and 5 than for months 7-9; (3) concentrations at the peak of surges was less for months 4 and 5 than for months 7 and 8; and (4) the length of the interpeak interval was longest for month 9. The lower mean FSH concentrations and lower nadir for month 4 may reflect, at least in part, the suppression associated with the more pronounced follicular waves for month 4 ; that is, the magnitude of the FSH nadir following emergence of a follicular wave and the interpeak and interwave intervals were greater when the largest follicle of a wave reached $\geq 10 \mathrm{~mm}$. On a temporal basis, the initial FSH decline $I$ and 2 days after the peak is attributable to small follicles $(6-9 \mathrm{~mm})$, whereas the continued decline is attributable to a selected dominant follicle $(\geq 10 \mathrm{~mm})$. Alternatively, the FSH surges may result from an inherent rhythm with the natural interval between surges lengthened when a large follicle develops. The inherent-rhythm possibility was raised by the periodic FSH surges without the development of follicular waves (no follicle $>5 \mathrm{~mm}$ ) in one heifer during a protracted period. It would appear that pregnancy would be a useful model for studying the follicle selection mechanism because of the natural occurrence of FSH surges with varied profiles and of largest follicles of various diameters.

In conclusion, folliculogenesis (follicles $\geq 4 \mathrm{~mm}$ ) after day 90 of pregnancy was characterized by the following: (1) emergence of follicles in waves throughout pregnancy; (2) a transitional decline in the prominence of waves over the first three waves after day 90 or between months 4 and 5; (3) a transient increase in number of follicles per wave or month during month 7 without a change in other wave characteristics; and (4) a gradual decrease in follicular activity over months 7 to 9, with minimal follicular activity during the last month of pregnancy. The peaks of FSH surges were closely associated temporally with the rhythmic emergence of follicular waves during the last two-thirds of pregnancy, as shown by the following: (1) highest mean FSH concentrations on the day of wave emergence; (2) significant temporal association between the peaks of identified FSH surges and wave emergence; and (3) agreement between the duration of interpeak intervals between identified FSH surges and the duration of interwave intervals. In waves in which the largest follicle reached $\geq 10 \mathrm{~mm}$, compared with waves with largest follicle $6-9 \mathrm{~mm}$, the interwave intervals and interpeak intervals were longer and the concentrations of FSH at the nadir following the stimulatory surge were lower. Surges of FSH were also found during periods of follicular quiescence (no follicles $>5 \mathrm{~mm}$ ).

This research was supported by the College of Agricultural and Life Sciences, University of Wisconsin and USDA grant No. 9401480. The authors thank $\mathrm{C}$. Bartol for manuscript preparation.

\section{References}

Adams GP, Matteri RL, Kastelic JP, Ko JCH and Ginther OJ (1992) Associations between surges of follicle-stimulating hormone and the emergence of follicular waves in heifers Journal of Reproduction and Fertility 94 177-188

Adams GP, Evans ACO and Rawlings NC (1994) Follicular waves and circulating gonadotrophins in 8-month-old prepubertal heifers Journal of Reproduction and Fertility $10027-33$ 
Bergfelt DR and Ginther OJ (1993) Relationships between FSH surges and follicular waves during the estrous cycle in mares Theriogenology 39 781-796

Bergfelt DR, Kastelic IP and Ginther OJ (1991) Continued periodic emergence of follicular waves in nonbred progesterone-treated heifers Animal Reproduction Science 24 193-204

Bodensteiner KJ, Kot K, Wiltbank MC and Ginther OJ (1996) Synchronization of emergence of follicular waves in cattle Theriogenology 45 1115-1128

Clifton DK and Steiner RA (1983) Cycle detection: a technique for estimating the frequency and amplitude of episodic fluctuations in blood hormone and substrate concentrations Endocrinology 112 1057-1064

Dominguez MM (1995) Effects of body condition, reproductive status and breed on follicular population and oocyte quality in cows Theriogenology $\mathbf{4 3}$ $1405-1418$

Ginther OJ and Bergfelt DR (1992) Associations between FSH concentrations and major and minor follicular waves in pregnant mares Theriogenology 38 $807-821$

Ginther OJ and Bergfelt DR (1993) Growth of small follicles and concentrations of FSH during the equine oestrous cycle Journal of Reproduction and Fertility 99 105-111

Ginther OJ and Kot K (1994) Follicular dynamics during the ovulatory season in goats Theriogenology 42 987-1001

Ginther OJ, Knopf L and Kastelic JP (1989a) Temporal associations among ovarian events during bovine oestrous cycles with two and three follicular waves Journal of Reproduction and Fertility 87 223-230

Ginther OJ, Knopf L and Kastelic JP (1989b) Ovarian follicular dynamics in heifers during early pregnancy Biology of Reproduction 41 247-254

Ginther OJ, Kot K and Wiltbank MC (1995) Associations between emergence of follicular waves and fluctuations in FSH concentrations during the estrous cycle in ewes Theriogenology 43 689-703
Gong JG, Bramley TA, Gutierrez CG, Peters AR and Webb R (1995) Effects of chronic treatment with a gonadotrophin-releasing hormone agonist on peripheral concentrations of FSH and $\mathrm{LH}$, and ovarian function in heifers Journal of Reproduction and Fertility 105 263-270

Knopf L, Kastelic JP, Schallenberger E and Ginther OJ (1989) Ovarian follicular dynamics in heifers: test of two-wave hypothesis by ultrasonically monitoring individual follicles Domestic Animal Endocrinology 6 111-119

Matteri RL, Bridson WE, Dierschke DJ, Wegner FH and Durning M (1992) The secretion of bioactive and immunoreactive follicle-stimulating hormone (FSH) and luteinizing hormone (LH) throughout the menstrual cycle of the rhesus monkey American Journal of Primatology 26 243-257

Pierson RA and Ginther OJ (1986) Ovarian follicular populations during early pregnancy in heifers Theriogenology $26649-658$

Pierson RA and Ginther OJ (1988) Ultrasonic imaging of the ovaries and uterus in cattle Theriogenology 29 21-37

Rexroad CE, Jr and Casida LE (1975) Ovarian follicular development in cows, sows and ewes in different stages of pregnancy as affected by number of corpora lutea in the same ovary Journal of Animal Science 41 1090-1097

Rüsse I (1971) Size of corpus luteum and follicular activity during pregnancy in cows and sheep Zuchthyg 6 126-134

Schallenberger E, Rampp J and Walters DL (1985) Gonadotrophins and ovarian steroids in cattle. II. Pulsatile changes of concentrations in the jugular vein throughout pregnancy Acta Endocrinologica 108 322-330

Sokal RR and Rohlf FJ (1969) Biometry p 83. WH Freeman and Company, San Francisco

Sunderland SJ, Crowe MA, Boland MP, Roche JF and Ireland JJ (1994) Selection, dominance and atresia of follicles during the oestrous cycle of heifers Journal of Reproduction and Fertility $101547-555$ 